\title{
Intravitreal ziv-aflibercept for macular edema following retinal vein occlusion
}

\author{
This article was published in the following Dove Press journal: \\ Clinical Ophthalmology \\ 22 September 2016 \\ Number of times this article has been viewed
}

\author{
Remya Paulose' \\ Jay Chhablani' \\ Chintan J Dedhia' \\ Michael W Stewart ${ }^{2}$ \\ Ahmad M Mansour ${ }^{3,4}$ \\ 'Smt. Kanuri Santhamma Centre for \\ Vitreoretinal Diseases, LV Prasad \\ Eye Institute, Hyderabad, India; \\ ${ }^{2}$ Department of Ophthalmology, \\ Mayo Clinic, Jacksonville, FL, USA; \\ ${ }^{3}$ Department of Ophthalmology, \\ American University of Beirut, \\ ${ }^{4}$ Department of Ophthalmology, Rafic \\ Hariri University Hospital, Beirut, \\ Lebanon
}

\begin{abstract}
Aim: To report the efficacy of intravitreal ziv-aflibercept injections in eyes with macular edema due to retinal vein occlusions (RVOs).

Methods: Consecutive patients with persistent or recurrent macular edema (central macula thickness $>250 \mu \mathrm{m}$ ) due to RVO were enrolled in this prospective study. Study eyes received intravitreal injections of ziv-aflibercept $(1.25 \mathrm{mg} / 0.05 \mathrm{~mL})$ at baseline. Patients were reassessed monthly for 4 months and given additional injections pro re nata for worsening bestcorrected visual acuity (BCVA), intraretinal edema or subretinal fluid seen on spectral domain optical coherence tomography, or central macular thickness (CMT) measurements $>250 \mu \mathrm{m}$. The primary endpoint was improvement in mean CMT at 4 months. Secondary endpoints included improvement in mean BCVA, and ocular and systemic safety signals.

Results: Nine eyes (five central and four branch RVOs) of nine patients were enrolled. The mean \pm standard deviation CMT decreased from $604 \pm 199 \mu \mathrm{m}$ at baseline to $319 \pm 115 \mu \mathrm{m}$ $(P=0.001)$ at 1 month and to $351 \pm 205 \mu \mathrm{m}(P=0.026)$ at 4 months. The mean BCVA did not improve significantly from baseline $(1.00 \operatorname{LogMAR})$ to the 1 -month $(0.74 \operatorname{LogMAR} ; P=0.2)$ and 4-month ( $0.71 \operatorname{LogMAR;} P=0.13$ ) visits. No safety signals were noted.

Conclusion: In this small prospective study, intravitreal ziv-aflibercept significantly improved mean CMT in eyes with persistent or recurrent macular edema due to RVOs. Prospective, randomized trials comparing ziv-aflibercept with standard pharmacotherapy are needed to better define efficacy and safety.
\end{abstract}

Keywords: ziv-aflibercept, retinal vein occlusion, cystoid macular edema

\section{Introduction}

Macular edema due to retinal vein occlusions (RVOs), the second most common retinal vascular condition, frequently results in significant loss of best-corrected visual acuity (BCVA). Intravitreal pharmacotherapy with corticosteroids and drugs that bind vascular endothelial growth factor (VEGF) usually resolves edema and improves BCVA better than observation in eyes with central retinal vein occlusion $(\mathrm{CRVO})^{1-4}$ and better than laser photocoagulation in eyes with branch retinal vein occlusion (BRVO). ${ }^{5,6}$ Although most of these eyes respond favorably to first-line intravitreal pharmacotherapy, improvements are usually transient ${ }^{7,8}$ and some eyes experience no improvement with available therapy. Achieving and maintaining a satisfactory clinical response usually becomes an expensive, long-term process that often challenges patient compliance.

Aflibercept (Eylea ${ }^{\circledR}$, Regeneron, Tarrytown, NY, USA) is the newest anti-VEGF drug that has been approved for the treatment of macular edema due to RVO. This recombinant fusion protein, composed of extra-cytoplasmic, native-receptor VEGFbinding sequences from VEGF receptor (VEGFR) 1 and VEGFR2, ${ }^{9}$ binds VEGF ${ }_{165}$
Correspondence: Ahmad M Mansour Department of Ophthalmology, American University of Beirut, POB I I3-6044,

Beirut, Lebanon

Tel +96I I 3377633

Email ammansourmd@gmail.com
Clinical Ophthalmology 2016:10 1853-1858

1853

Dovepress in

http://dx,doi.org/10.21471OPTH.S116343 (c) 1 (7) 2016 Paulose et al. This work is published and licensed by Dove Medical Press Limited. The full terms of this license are available at https://www.dovepress.com/terms.php hereby accept the Terms. Non-commercial uses of the work are permitted without any further permission from Dove Medical Press Limited, provided the work is properly attributed. For permission for commercial use of this work, please see paragraphs 4.2 and 5 of our Terms (https://www.dovepress.com/terms.php). 
100 times tighter than either bevacizumab or ranibizumab, and also binds isoforms of VEGF-B and placental growth factor. ${ }^{10}$ The VIBRANT trial demonstrated that aflibercept was superior to laser photocoagulation in eyes with BRVO, ${ }^{6}$ and the COPERNICUS and GALILEO trials showed that aflibercept was superior to sham in eyes with CRVO.,

Aflibercept's strong VEGF-binding affinity may provide a therapeutic advantage over other VEGF-binding drugs when treating vascular conditions with high intravitreal VEGF concentrations such as diabetic macular edema (DME), proliferative diabetic retinopathy, and RVOs, but very few randomized, multicenter, double-masked trials have directly compared aflibercept with bevacizumab and ranibizumab. DRCR.net Protocol T showed that for eyes with DME, aflibercept produced superior 1-year improvements in BCVA compared to bevacizumab and ranibizumab, ${ }^{11}$ though statistical superiority was not maintained through 2 years. ${ }^{12}$ The ongoing SCORE-2 trial compares aflibercept with bevacizumab for primary treatment of macular edema due to RVOs, with aflibercept also serving as rescue therapy for eyes that fail to respond favorably to bevacizumab (https:// clinicaltrials.gov/ct2/show/NCT01969708).

Aflibercept use in developing countries is limited due to its high cost and narrow regulatory approvals. Our group recently reported the short-term safety of intravitreal zivaflibercept (Zaltrap ${ }^{\circledR}$; Regeneron, Tarrytown, NY, USA), which has the identical molecular structure as aflibercept, in eyes with neovascular age-related macular degeneration (nAMD). ${ }^{13-15}$ The purpose of the study described in this manuscript was to evaluate the 4-month safety and efficacy of intravitreal ziv-aflibercept in eyes with RVO that had previously received intravitreal pharmacotherapy.

\section{Methods}

This two-center, open-label, nonrandomized, single-arm, prospective study enrolled patients between April 2015 and October 2016. Institutional Review Board approval was granted at LV Prasad Eye Institute, Hyderabad, India and Rafic Hariri University Hospital, Beirut, Lebanon and the study adhered to the tenets of the Declaration of Helsinki. Written informed consent to participate in the study was given by each patient after learning about the study methodology and the possible risks and benefits. The clinical trial registry number is NCT02486484.

\section{Inclusion and exclusion criteria}

Key inclusion criteria included previously treated (intravitreal bevacizumab, ranibizumab, dexamethasone insert, or laser photocoagulation) macular edema due to RVO that either recurred since the last treatment or never satisfactorily resolved after at least 3 months of therapy. A central macular thickness (CMT) of at least $250 \mu \mathrm{m}$ on spectral-domain optical coherence tomography (SD-OCT) was required for enrollment.

Exclusion criteria included uncontrolled systemic vascular disease (including systemic arterial hypertension and diabetes mellitus), glaucoma, vitreomacular interface disorders in the study eye that could limit resolution of edema and improvement in BCVA, and previous vitrectomy.

\section{Clinical evaluations and treatments}

Clinical examinations included determination of bestcorrected Snellen visual acuity, intraocular pressure measurement with applanation tonometry, slit-lamp examination of the anterior segment, biomicroscopic and indirect ophthalmoscopic evaluation of the fundus, and SD-OCT scanning of the central macula. CMT was measured with the $3 \mathrm{D}$ OCT-2000 FA plus Topcon ${ }^{\circledR}$ (Topcon, Tokyo, Japan) in Lebanon and with the Cirrus ${ }^{\circledR}$ (Carl Zeiss Meditec, Dublin, CA, USA) in India. All CMT measurements taken with the Topcon scanner were converted to Cirrus measurements by adding $23.6 \mu \mathrm{m}$, consistent with the normalization proposed by Lammer et al. ${ }^{16}$ Intravenous fluorescein angiography was performed at baseline.

Ziv-aflibercept was prepared and injected according to standardized protocols. ${ }^{13}$ After instillation of topical anesthesia and povidone-iodine solution onto the conjunctiva, a sterile eyelid retractor was positioned. Ziv-aflibercept (1.25 mg/0.05 mL) was injected through the sclera (3.5-4 mm posterior to the limbus) into the mid-vitreous. All study eyes received ziv-aflibercept injections at baseline.

Patients received comprehensive eye examinations and SD-OCT macula scans monthly for 4 months. Additional injections of ziv-aflibercept were performed on a pro re nata basis if the BCVA worsened, intraretinal edema or subretinal fluid was noted, or the CMT measured $>250 \mu \mathrm{m}$.

\section{Outcomes}

The primary outcome measure was the change in mean CMT from baseline to month 4. Secondary outcomes included any change in the mean BCVA at 4 months and ocular and systemic safety signals.

\section{Statistical analyses}

Statistical analyses were performed using SPSS version 22 (IBM Corporation, Chicago, IL, USA). Snellen BCVA values were converted into LogMAR for statistical analysis. Changes in CMT and BCVA were assessed with the 
Wilcoxon-signed rank test and $P$-values of $<0.05$ were deemed statistically significant.

\section{Results}

\section{Baseline characteristics}

Nine eyes (five eyes with CRVO and four eyes with BRVO) of nine patients were enrolled in this study. Baseline characteristics of the patients and study eyes are listed in Table 1.

The mean \pm standard deviation age of patients in the cohort was $64 \pm 8$ years and eight of the nine ( $89 \%$ ) patients were males. Diabetes mellitus and systemic arterial hypertension were each found in six patients $(67 \%)$, coronary artery disease in two (22\%), and hyperhomocysteinemia in one (11\%). None of the patients had features of diabetic retinopathy in the non-study eyes.

Prior to enrollment in this study, the patients had fluorescein angiography and had previously been treated with laser photocoagulation and intravitreal injections of bevacizumab, ranibizumab, triamcinolone, or dexamethasone implant (Table 1). The median number of prior intravitreal injections was 5 (range: 2-24) and the mean duration since the last injection was $11 \pm 20$ months (range: $1-63$ months).

\section{Study treatments}

The mean number of ziv-aflibercept injections administered during the 4-month study period was $2.3 \pm 0.9$ (range: $1-4$ ). The mean treatment-free interval after switching to zivaflibercept was $1.9 \pm 0.2$ months (range: $1-2$ months). Figure 1 shows the treatment response of a representative case.

\section{Visual acuity}

The mean BCVA at study entry was 1.0 LogMAR (Snellen equivalent: 20/200) with a range of 0.4 to 1.7 LogMAR (Snellen equivalent: $20 / 50$ to 20/1,200). At 1 month, the mean BCVA improved to $0.74 \operatorname{LogMAR}$ (Snellen equivalent: 20/120; $P=0.2$ ) and at 4 months to 0.71 LogMAR (Snellen equivalent: $20 / 100 ; P=0.13)$. Visual acuity improved in most eyes (eight of nine) at 4 months (median improvement from 20/160 to 20/80), with greater changes seen in the eyes that were last treated within 3 months (improvement in median BCVA from 20/180 to 20/90) compared to those last treated $>12$ months previously (median improvement from $20 / 100$ to $20 / 80$ ).

\section{Macular thickness}

The mean CMT at baseline $(603 \pm 199 \mu \mathrm{m})$ decreased to $319 \pm 115 \mu \mathrm{m}(P=0.001)$ at 1 month and to $351 \pm 205 \mu \mathrm{m}$ $(P=0.026)$ at 4 months. Significant improvements in CMT occurred both in eyes that had received intravitreal pharmacotherapy only 1 to 3 months previously (mean improvement in CMT from $587 \mu \mathrm{m}$ to $370 \mu \mathrm{m}$ ) and also in eyes that had last been treated over 1 year prior (mean improvement in CMT from 637 to $361 \mu \mathrm{m}$ ). Changes in BCVA and CMT throughout the study period are shown in Figure 2.

\section{Safety}

One eye (Case 9) developed minimal anterior chamber flare 2 days after the fourth injection. Cases 1-8 did not develop intraocular inflammation. None of the patients experienced systemic adverse events that could be attributed to intravitreal ziv-aflibercept. The mean intraocular pressure did not change from baseline $(13.2 \pm 3.3 \mathrm{mmHg})$ to month 4 (13.4 $\pm 2.3 \mathrm{mmHg})$.

\section{Discussion}

In this study of patients with previously treated macular edema due to RVOs, we found that switching to ziv-aflibercept

Table I Clinical characteristics of study patients

\begin{tabular}{|c|c|c|c|c|c|c|c|c|c|c|c|}
\hline \multirow[t]{2}{*}{ Case } & \multirow[t]{2}{*}{ Age/sex } & \multirow{2}{*}{$\begin{array}{l}\text { Disease } \\
\text { duration } \\
\text { (months) }\end{array}$} & \multirow{2}{*}{$\begin{array}{l}\text { Time since } \\
\text { last injection } \\
\text { (months) }\end{array}$} & \multirow{2}{*}{$\begin{array}{l}\text { Number of } \\
\text { ziv-aflibercept } \\
\text { injections }\end{array}$} & \multirow[t]{2}{*}{$\begin{array}{l}\text { Previous } \\
\text { treatments }\end{array}$} & \multicolumn{3}{|c|}{$\begin{array}{l}\text { Best-corrected visual } \\
\text { acuity }\end{array}$} & \multicolumn{3}{|c|}{$\begin{array}{l}\text { Central macular thickness } \\
\text { (microns) }\end{array}$} \\
\hline & & & & & & Baseline & Month I & $\overline{\text { Month } 4}$ & Baseline & Month I & $\overline{\text { Month } 4}$ \\
\hline I & $81 / M$ & 66 & 63 & 3 & $2 B$ & $20 / 800$ & $20 / 800$ & $20 / 400$ & 558 & 437 & 302 \\
\hline $2^{*}$ & $60 / M$ & 30 & 12 & I & $2 \mathrm{~B}+2 \mathrm{TA}+\mathrm{SL}$ & $20 / 80$ & $20 / 80$ & $20 / 80$ & 664 & 428 & NA \\
\hline 3 & $65 / M$ & 30 & 2 & 2 & I2B+PRP+ID & $20 / 200$ & $20 / 100$ & $20 / 100$ & 834 & 193 & 173 \\
\hline 4 & $65 / M$ & 30 & 2 & 2 & I3B+PRP+ID & $20 / 200$ & $20 / 160$ & $20 / 100$ & 938 & 232 & 167 \\
\hline $5^{*}$ & $67 / M$ & 11 & 3 & 2 & $I B+I D+S L$ & $20 / 160$ & $20 / 80$ & $20 / 80$ & 560 & 445 & 428 \\
\hline $6^{*}$ & $77 / M$ & 46 & I & 2 & $5 B$ & $20 / 100$ & $20 / 80$ & $20 / 60$ & 443 & 386 & 266 \\
\hline 7 & $48 / M$ & 13 & I & 3 & $2 \mathrm{~B}+\mathrm{PRP}$ & $20 / 1,200$ & $20 / 160$ & $20 / 200$ & 329 & 173 & 766 \\
\hline 8* & $49 / M$ & 14 & I & 2 & $\mathrm{IR}+2 \mathrm{~B}+\mathrm{SL}$ & $20 / 50$ & $20 / 40$ & $20 / 40$ & 417 & NA & 354 \\
\hline 9 & $7 I / F$ & 56 & 15 & 4 & $2 I B+I R+I A$ & $20 / 100$ & $20 / 80$ & $20 / 80$ & 689 & 354 & 389 \\
\hline
\end{tabular}

Note: *Eyes with branch retinal vein occlusion, others were central retinal vein occlusion.

Abbreviations: A, intravitreal aflibercept (2 mg/0.05 mL); B, intravitreal bevacizumab (1.25 mg/0.05 mL); D, intravitreal dexamethasone insert; F, female; $M$, male; NA, not available; PRP, panretinal photocoagulation; $R$, intravitreal ranibizumab $(0.3 \mathrm{mg} / 0.05 \mathrm{~mL})$; $\mathrm{SL}$, sectoral laser; TA, intravitreal triamcinolone $(2 \mathrm{mg} / 0.1 \mathrm{~mL})$. 

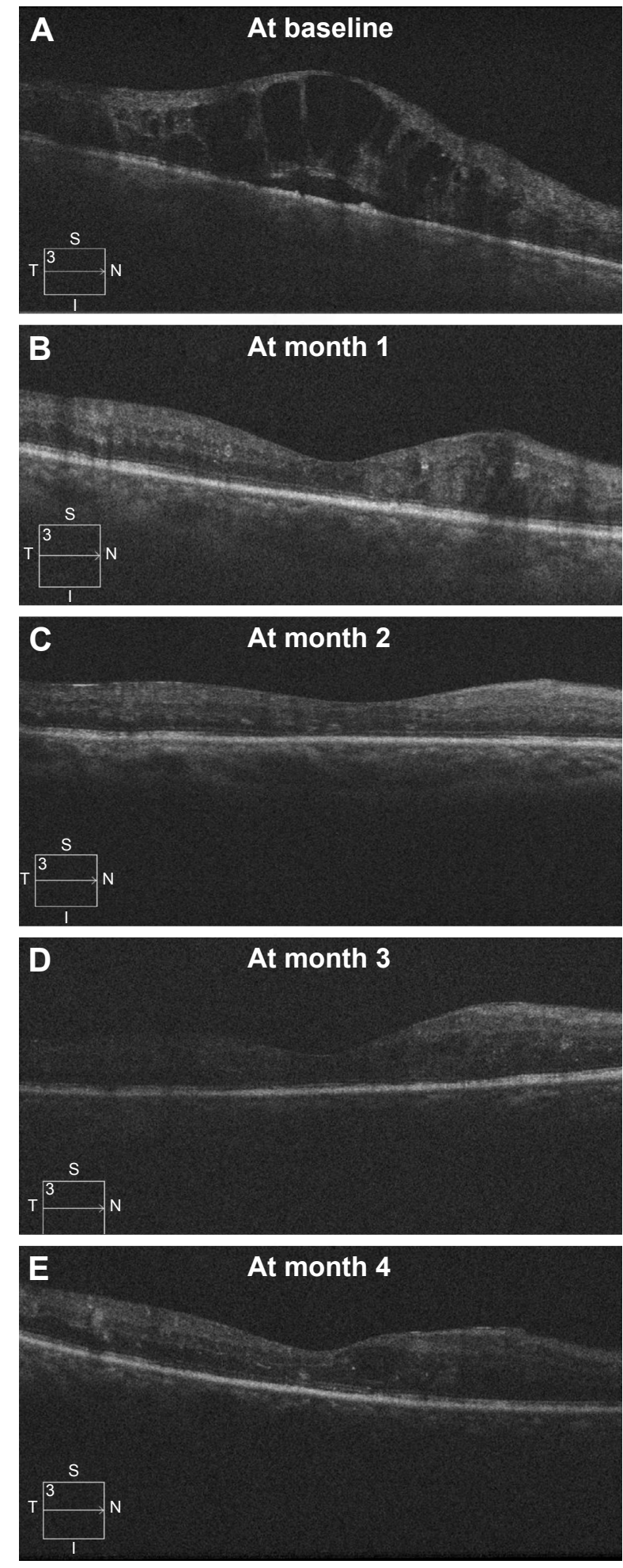

Figure I Serial linear OCT scan after intravitreal ziv-aflibercept injections. Notes: A 65-year-old male developed macular edema due to a CRVO. Over a 2.5-year period, he received 12 anti-vascular endothelial growth factor injections, intravitreal triamcinolone, and peripheral retinal photocoagulation. Upon entering this study, his visual acuity measured 20/200 with a central macular thickness of $938 \mu \mathrm{m}(\mathbf{A})$. Intravitreal ziv-aflibercept injections at baseline and month I resolved the macular edema (B and $\mathbf{C}$ ), after which he was observed until the study's primary temporal endpoint (D and E). His visual acuity improved to 20/60.

Abbreviations: CRVO, central retinal vein occlusion; OCT, optical coherence tomography; T, temporal; S, superior; N, nasal; I, inferior. resulted in significant improvements in macular edema and modest improvements in BCVA, most likely due to the chronicity of the disease at presentation.

The Phase III registration trials demonstrated that intravitreal ranibizumab and aflibercept are superior to standardof-care for the treatment of macular edema due to BRVO and CRVO. ${ }^{2-6}$ Bevacizumab has not been studied with the same rigor as ranibizumab and aflibercept but bevacizumab regimens appear to produce comparable improvements in macular edema and BCVA. ${ }^{17,18}$ Most eyes with RVO respond well to bevacizumab or ranibizumab but a small proportion fail to achieve satisfactory responses with initial therapy or experience an unacceptably early or frequent recurrence of edema. Small retrospective studies reported visual gains after switching to aflibercept but since standardized procedures and control arms were lacking, the significance of these findings is unclear. ${ }^{19,20}$ Nonetheless, switching incomplete responders to aflibercept appears to be a reasonable treatment option.

Surgeons in many developing countries cannot use aflibercept to treat RVOs because it may be excluded from the formularies of insurance plans or national health care plans and its high cost $(\$ 1,850$ US per dose) prevents many patients from paying out-of-pocket. In countries such as India, aflibercept has been approved for the treatment of nAMD but not yet for RVOs.

Just as off-label bevacizumab became an accepted, affordable treatment for chorioretinal vascular disorders, zivaflibercept could become a similar option in countries with limited access to aflibercept. Ziv-aflibercept was approved by the US Food and Drug Administration in August 2012 for the intravenous treatment of advanced colorectal carcinoma. ${ }^{21}$ Ziv-aflibercept is packaged in a single use $4 \mathrm{~mL}$ vial $(1.25 \mathrm{mg} / 0.05 \mathrm{~mL})$ and costs (\$512 US) substantially less than aflibercept and even slightly less than bevacizumab (4 mL vial costs $\$ 660$ ).

Buffering solutions in ziv-aflibercept produce a high osmolality $(1,000 \mathrm{mOsm} / \mathrm{kg})$ that is toxic to most cells. ${ }^{22}$ Concerns regarding hyperosmolality-induced retinal toxicity due to intravitreal ziv-aflibercept have been largely dispelled by recent publications. ${ }^{23}$ Case reports describing ziv-aflibercept treatment of nAMD, polypoidal choroidal vasculopathy, and CRVO identified no safety concerns. ${ }^{13,14,24}$ Mansour et al noted no ocular toxicity with intravitreal zivaflibercept in patients with DME and nAMD, and they posited that the small volume of high osmolality ziv-aflibercept $(0.05 \mathrm{~mL})$ is adequately diluted by the relatively large vitreous cavity $(4 \mathrm{~mL}) .{ }^{14}$ Chhablani et al noted no clinical 

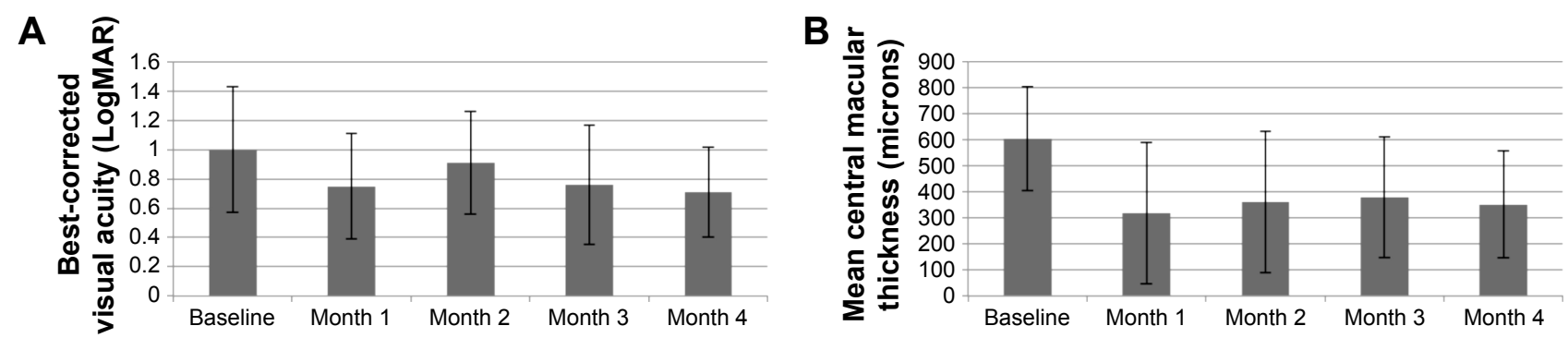

Figure 2 Mean best-corrected visual acuity (A) and mean central macular thickness (B) with standard deviation limits at each study visit. Notes: Mean best-corrected visual acuity improved through 4 months but changes were not statistically significant. Compared to baseline, mean central macular thickness was significantly better at each follow-up visit.

toxicity and detected no electroretinographic abnormalities in 12 eyes that received single injections of ziv-aflibercept for treatment-resistant nAMD. ${ }^{13}$

Most eyes in our study, whether last treated within the previous 3 months or more than a year prior, experienced decrease in macular edema. Visual acuity improvements favored eyes treated within the past 3 months but our small cohort is insufficiently powered to draw firm conclusions. Larger RVO trials suggest that even brief periods of undertreatment (as short as 6 months) may result in poorer longterm visual outcomes. ${ }^{2,4}$ Nonetheless, our results support the notion that RVO patients should be followed closely so that recurrent edema can be treated promptly.

The optimal dose of intravitreal ziv-aflibercept is not known. We injected $0.05 \mathrm{~mL}(1.25 \mathrm{mg})$ of undiluted zivaflibercept so that the small volume would minimize acute elevations in intraocular pressure. The approved dose of aflibercept $(2 \mathrm{mg} / 0.05 \mathrm{~mL})$ delivers $60 \%$ more drug than was used in our trial but smaller doses of aflibercept have not been reported in eyes with RVOs. Patients treated with $0.5 \mathrm{mg}$ aflibercept in the VIEW trials achieved comparable results to those receiving the $2 \mathrm{mg}$ dose, suggesting that dose size may not be a critical determinant of clinical response..$^{25}$ Dose range determinations with ziv-aflibercept continue as a higher dose $(2 \mathrm{mg} / 0.08 \mathrm{~mL})$ is being evaluated.

Our study has several strengths and weaknesses. To the best of our knowledge, this is the first prospective study to evaluate the safety and efficacy of ziv-aflibercept for macular edema due to RVOs. The study reports data gathered from more than one site but the small cohort prevents us from detecting statistically significant visual acuity changes. Because of the small cohort, we elected to analyze eyes with central RVO and branch RVO together, even though these conditions often have different baseline characteristics and responses to treatment. The mixed composition of the cohort - patients who were actively being treated for RVO and others whose last injections were at least 1 year prior - makes it difficult to use the data to create firm indications for switching patients to ziv-aflibercept. The 4-month primary endpoint is brief and longer follow-up periods are needed.

Despite the shortcomings of this pilot study, we believe that these data support the use of ziv-aflibercept in selected patients with RVOs. This study adds to the growing body of data supporting the safety of intravitreal ziv-aflibercept in eyes with chorioretinal vascular conditions. Whether intravitreal ziv-aflibercept would be an acceptable option in countries where aflibercept has already been approved for the treatment of RVOs is unclear, but in lower income countries that have not approved aflibercept, ziv-aflibercept could become a cost-effective alternative to other anti-VEGF drugs. Larger, multicenter, prospective, controlled studies are needed to better define the efficacy of ziv-aflibercept in patients with macular edema due to RVOs.

\section{Disclosure}

The authors report no conflicts of interest in this work.

\section{References}

1. Haller JA, Bandello F, Belfort R Jr, et al. Dexamethasone intravitreal implant in patients with macular edema related to branch or central retinal vein occlusion twelve-month study results. Ophthalmology. 2011;118(12): 2453-2460

2. Campochiaro PA, Brown DM, Awh CC, et al. Sustained benefits from ranibizumab for macular edema following central retinal vein occlusion: twelve-month outcomes of a phase III study. Ophthalmology. 2011; 118(10):2041-2049.

3. Heier JS, Clark WL, Boyer DS, et al. Intravitreal aflibercept injection for macular edema due to central retinal vein occlusion: two-year results from the COPERNICUS study. Ophthalmology. 2014;121(17):1414-1420.

4. Ogura Y, Roider J, Korobelnik JF. et al. Intravitreal aflibercept for macular edema secondary to central retinal vein occlusion: 18-month results of the phase 3 GALILEO study. Am J Ophthalmol. 2014;158(5):1032-1038.

5. Brown DM, Campochiaro PA, Bhisitkul RB, et al. Sustained benefits from ranibizumab for macular edema following branch retinal vein occlusion: 12-month outcomes of a phase III study. Ophthalmology. 2011; 118(8):1594-1602.

6. Campochiaro PA, Clark WL, Boyer DS, et al. Intravitreal aflibercept for macular edema following branch retinal vein occlusion: the 24-week results of the VIBRANT study. Ophthalmology. 2015;122(3):538-544. 
7. Heier JS, Campochiaro PA, Yau L, et al. Ranibizumab for macular edema due to retinal vein occlusions: long-term follow-up in the HORIZON trial. Ophthalmology. 2012;119(4):802-809.

8. Campochiaro PA, Sophie R, Pearlman J, et al; RETAIN Study Group. Long-term outcomes in patients with retinal vein occlusion treated with ranibizumab. the RETAIN study. Ophthalmology. 2014;121(1): 209-219.

9. Holash J, Davis S, Papadopoulos N, et al. VEGF-Trap: a VEGF blocker with potent antitumor effects. Proc Natl Acad Sci U S A. 2002;99(17): 11393-11398.

10. Papadopoulos N, Martin, Ruan Q, et al. Binding and neutralization of vascular endothelial growth factor (VEGF) and related ligands by VEGF Trap, ranibizumab and bevacizumab. Angiogenesis. 2012;15(2): 171-185.

11. Diabetic Retinopathy Clinical Research Network, Wells JA, Glassman AR, Ayala AR, et al. Aflibercept, bevacizumab, or ranibizumab for diabetic macular edema. N Engl J Med. 2015;372(13):1193-1203.

12. Wells JA, Glassman AR, Ayala AR, et al; Diabetic Retinopathy Clinical Research Network. Aflibercept, bevacizumab, or ranibizumab for diabetic macular edema: Two-year results from a comparative effectiveness randomized clinical trial. Ophthalmology. 2016;123(6): 1351-1359.

13. Chhablani J, Narayanan R, Mathai A, Yogi R, Stewart M. Short-term safety profile of intravitreal ziv-Aflibercept. Retina. 2016;36(6):1126-1131.

14. Mansour AM, Al-Ghadban SI, Yunis MH, El-Sabban ME. Ziv-aflibercept in macular disease. Br J Ophthalmol. 2015;99(8):1055-1059.

15. Mansour AM, Chhablani J, Antonios RS, et al. Three-month outcome of ziv-aflibercept for exudative age-related macular degeneration. Br J Ophthalmol. Epub 2016 Mar 30.

16. Lammer J, Scholda C, Prunte C, Benesch T, Schmidt-Erfurth U, Bolz M. Retinal thickness and volume measurements in diabetic macular edema: a comparison of four, optical coherence tomography systems. Retina. 2011;31(1):48-55.
17. Prager F, Michels S, Kriechbaum K, et al. Intravitreal bevacizumab (Avastin) for macular oedema secondary to retinal vein occlusion: 12-month results of a prospective clinical trial. Br J Ophthalmol. 2009; 93(4):452-456.

18. Epstein DL, Algvere PV, von Wendt G, Seregard S, Kvanta A. Benefit from bevacizumab for macular edema in central retinal vein occlusion: twelve-month results of a prospective, randomized study. Ophthalmology. 2012;119(12):2587-2591.

19. Papakostas TD, Lim L, van Zyl T, et al. Intravitreal aflibercept for macular oedema secondary to central retinal vein occlusion in patients with prior treatment with bevacizumab or ranibizumab. Eye (Lond). 2016;30(1):79-84.

20. Lehmann-Clarke L, Dirani A, Mantel I, Ambresin A. The effect of switching ranibizumab to aflibercept in refractory cases of macular edema secondary to ischemic central vein occlusion. Klin Monbl Augenheilkd. 2015;232(4):552-555.

21. Chung C, Pherwani N. Ziv-aflibercept: a novel angiogenesis inhibitor for the treatment of metastatic colorectal cancer. Am J Health Syst Pharm. 2013;70(21):1887-1896.

22. Marmor MF, Martin LJ, Tharpe S. Osmotically induced retinal detachment in the rabbit and primate. electron miscoscopy of the pigment epithelium. Invest Ophthalmol Vis Sci. 1980;19(9):1016-1029.

23. Malik D, Tarek M, Caceres del Carpio J, et al. Safety profiles of antiVEGF drugs: bevacizumab, ranibizumab, aflibercept and ziv-aflibercept on human retinal pigment epithelium cells in culture. Br J Ophthalmol. 2014;98 Suppl 1:11-16.

24. Chhablani J. Intravitreal ziv-aflibercept for recurrent macular edema secondary to central retinal venous occlusion. Indian J Ophthalmol. 2015; 63(5):469-470.

25. Schmidt-Erfurth U, Kaiser PK, Korobelnik JF, et al. Intravitreal aflibercept injection for neovascular age-related macular degeneration: ninety-six-week results of the VIEW studies. Ophthalmology. 2014; 121(1):193-201.
Clinical Ophthalmology

\section{Publish your work in this journal}

Clinical Ophthalmology is an international, peer-reviewed journal covering all subspecialties within ophthalmology. Key topics include: Optometry; Visual science; Pharmacology and drug therapy in eye diseases; Basic Sciences; Primary and Secondary eye care; Patient Safety and Quality of Care Improvements. This journal is indexed on Submit your manuscript here: http://www.dovepress.com/clinical-ophthalmology-journal

\section{Dovepress}

PubMed Central and CAS, and is the official journal of The Society of Clinical Ophthalmology (SCO). The manuscript management system is completely online and includes a very quick and fair peer-review system, which is all easy to use. Visit http://www.dovepress.com/ testimonials.php to read real quotes from published authors. 